\title{
THE GLOBAL ENERGY CHALLENGE: STILL FUEL FOR PROGRESS?
}

\author{
ERIK JARLSBY \\ Erik Jarlsby AS, Norway.
}

\begin{abstract}
This paper summarises the key challenges for the global energy sector to fulfil its essential role in the world with a forward perspective from 2014 to 2040. The paper draws on scenarios and other analyses developed by leading institutions and firms. The global availability of extractive energy resources is not likely constrain global progress on human development in the chosen time perspective, but the supplies of oil and gas can come under strain and produce price shocks from time to time resulting from events affecting the supply system. A more severe challenge arises from the impacts of energy-related emissions on the global climate. Actions are possible on the arenas of technology development, enterprise and political governance, which will significantly reduce such risks while fulfilling the energy sector's contribution to improve human conditions. Six such issues of technology development are highlighted, and two issues of political governance: appropriate pricing of energy and emissions, and development of energy efficient cities.
\end{abstract}

Keywords: Climate change, energy policy, oil resources, sustainability.

\section{INTRODUCTION}

This paper aims to provide a broad overview and an appropriate perspective for the large global challenges for energy. Section 2 introduces the energy sector's global mission and challenges, i.e. the contributions that the sector is called upon to make to improve human conditions. The section reviews the issues of energy as an enabler of human development and the climate issue related to energy use. Section 3 assesses the global prospects for energy to 2040 by reviewing projections for energy use, emissions affecting the climate and the availability of hydrocarbons. Section 4 introduces selection issues, which can become part of the solution for the world's large challenges to which the energy sector must contribute. These are issues in the arenas of technology development, enterprise and political governance.

\section{THE ENERGY SECTOR AND ITS GLOBAL MISSION}

\subsection{Energy sector: delineation}

For the purpose of a discussion of global energy challenges, the energy sector can be understood broadly as comprising all enterprises that supply energy products in the forms of combustible fuels, electricity and heat, as well as those providing goods, services, knowledge and governance in support of energy supply. This broad view of the energy sector includes enterprises (owned by commercial investors or by the government), governmental institutions as well as learning institutions. Among the enterprises, there are the oil and gas producing firms, which have usually pursued rather different strategies and modes of operations from the 'utility' oriented suppliers of electricity, another essential part of the energy 
sector. There are suppliers of systems for providing renewable energy, and more generally, the engineering firms and other suppliers of all goods and services required for extracting and supplying energy.

\subsection{Energy as an enabler of human development}

It is well known that energy, supplied in various suitable forms, essentially supports economic development and improving human conditions. Figure 1 is a plot of 66 countries, some of which are identified by names, in terms of their energy consumption per person and gross domestic product per person at purchasing power parity. The total world result is also shown. The scatter of plots broadly around a rising direction indicates a tendency for high-income economies to consume more energy than low-income ones. This observation is supported by the correlation coefficient of 0.72 between the two data sets.

As an example from Fig. 1, Japan's energy consumption per person is eight times that of India's, while Japan's GDP per person is nine times that of India's. For India in the future to approach Japan's level of affluence, there is little doubt that India's energy consumption will have to increase significantly. It will not necessarily have to rise eightfold, as exposed below.

The benefits that users of energy seek are not obtained directly from energy as such, but from various functionalities enabled by energy in combination with relevant equipment: mobility for persons, movement of goods, industrial process heat, light, comfortable indoor temperature, electric and electronic applications, etc. For each type of functionality, the applied equipment and technology can vary in energy efficiency, i.e. the ratio between energy spent and functionality obtained, whose improvement has been an important aim of technology development since the 1970s.

While indicating a positive relationship between income and energy consumption, Fig. 1 also suggests that this relationship is not linear. Switzerland has more than double the income per person as the Czech Republic, but consumes less energy per person. Economic structure

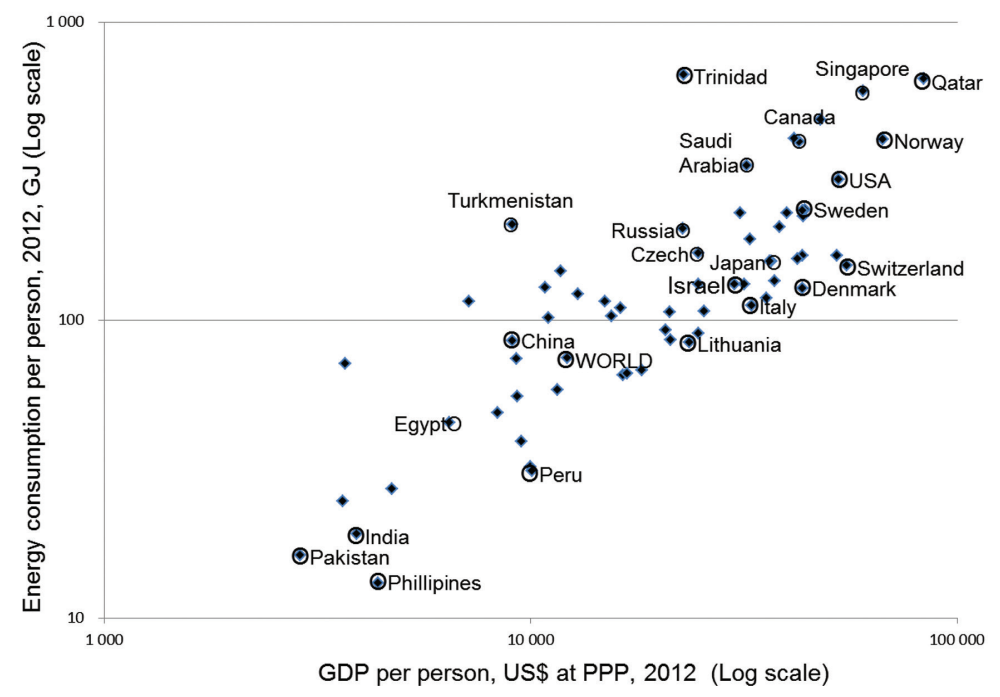

Figure 1: Energy consumption and production per person in selected countries. Based on data from the World Bank database and BP statistics [20]. 
is at play here: an economy dominated by service sectors can be wealthy while having modest energy consumption. Russia's rather high energy consumption relative to its economy is clearly driven in part by the geographical realities of cold winters and long distances. Countries having large energy production tend to also have high energy consumption relative to their economies, which draws two possible explanations: that significant amounts of energy are spent in producing usable forms of energy and (or) that governments having abundant domestic energy tend to keep its prices low, thereby stimulating practices of high-energy consumption.

Figure 2 relates the energy consumption of nations to the Human Development Index (HDI) [1], which incorporates assessments of a broad range of social qualities of nations. The HDI is also positively correlated with national energy consumption, but the wider scattering of plots compared with Fig. 1 suggests that energy consumption is less strongly linked to human development broadly assessed than it is linked to the economic dimension of development.

As seen from Fig. 2, Japan, Switzerland and Denmark are among the best performers in terms of HDI, while consuming energy in amounts which are far from the highest (but also far from the lowest) in international comparison. Japan and Switzerland have historically had to procure most of their energy from abroad. Denmark has been a modest net oil exporter of oil since 1997 but has continued to impose large taxes on oil consumption. All three countries pursued energy policies which ensured adequate availability of energy for their economies, but without trying to achieve competitive advantage by making energy cheap. Energy has been an enabler, but not a prime driver, of human development and of economic growth in these countries.

For some countries that are large net exporters of oil and gas, one can observe a combination of large energy consumption and unimpressive results on HDI. In such cases, energy prices for domestic consumption are often subsidised. Established economic theory applied

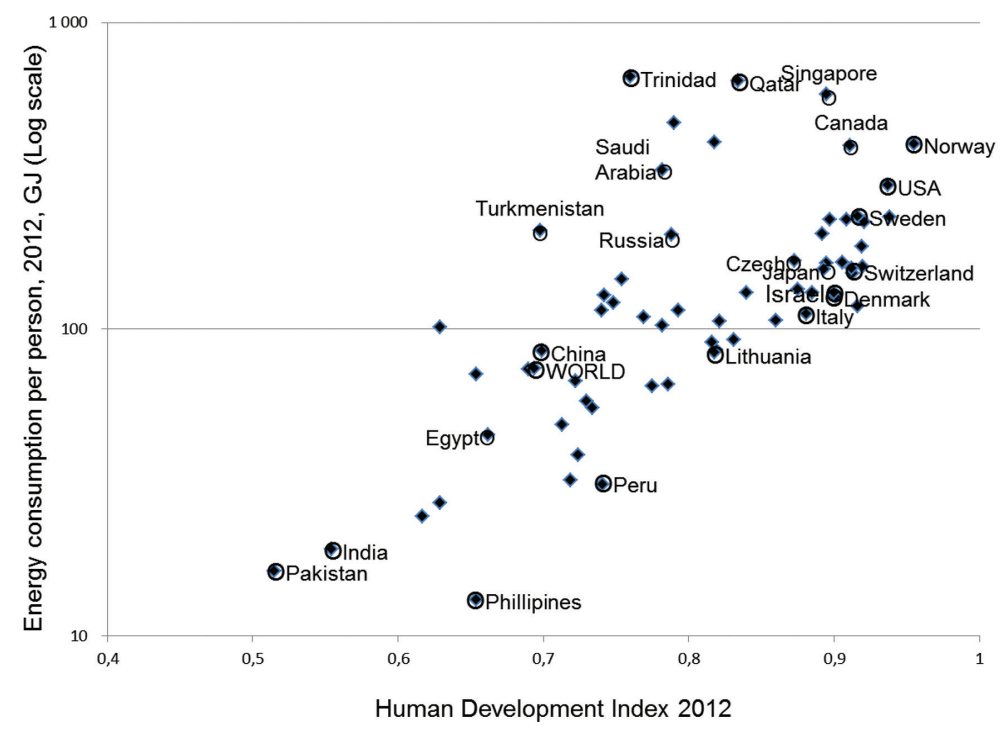

Figure 2: Energy consumption and Human Development Index for selected countries. Based on data from UNDP [1] and BP [4]. 
to such cases identifies two reasons for high-energy consumption which does not help human development or economic growth: Weak stimuli for energy efficiency and buyer trade-offs towards more energy-intensive functionalities.

The argument made above can be concluded as follows: energy is an important enabler of economic growth and general human development. The people in this world who currently live in conditions of low income and low human development will need more energy to improve their conditions in the future. But higher energy consumption does not automatically improve human conditions. A high level of human development can be attained with more or less energy consumption, depending on the efficiency of energy applications and trade-offs between more or less energy intensive functionalities.

\subsection{Energy and environmental sustainability}

Emissions of $\mathrm{CO}_{2}$ from combustion of coal, oil and gas are associated with dangerous changes to the global climate. Three assertions are central to this association:

1. The global climate is undergoing significant changes.

2. These climate changes are caused, at least in part, by human activity, including emissions to the atmosphere resulting from the use of coal, oil and gas.

2. The climate changes are set on a path towards inflicting serious damage on natural environments and societies of the world.

The Intergovernmental Panel of Climate Change (IPCC) is the leading international institution for assessment of climate change, drawing on large scientific capabilities from many nations. It has delivered substantial support for the three assertions above, while acknowledging that the underlying science is complex and carries uncertainties.

The assertion of ongoing climate change is supported by numerous observations and reconstructed time data series describing conditions of the earth's surfaces, waters and atmosphere. The average global surface temperature over sea and land is estimated to have risen by $0.85^{\circ} \mathrm{C}$ since 1885 . Warming has occurred over almost the entire globe, though to varying extents. The global mean sea level is estimated to have risen by $19 \mathrm{~cm}$ since 1901 . The $90 \%$ confidence intervals for these estimates are stated as $0.65^{\circ} \mathrm{C}$ to $1.06^{\circ} \mathrm{C}$ for average global warming since 1885 , and $17-21 \mathrm{~cm}$ for sea-level rise since 1901 [2].

The assertion of human influence on the climate is supported by measurements of atmospheric components such as $\mathrm{CO}_{2}$ as shown in Fig. 3, in combination with data models that provide explanations for the relationships between observed parameters. Figure 3 represents the measurements of $\mathrm{CO}_{2}$ in the atmosphere at Mauna Loa, a mountain on the Hawaii islands in the Pacific Ocean. The air there is sufficiently remote from significant local influences so as to be representative of the global atmosphere. As seen from the figure, the $\mathrm{CO}_{2}$ concentration is on steady and rising trend, having increased by some $20 \%$ since the 1970 s. Combustion of coal, oil and gas is the likely main cause of the increase, though there are also other causes, notably the conversion of large areas of forest to arable land. Figure 3 also shows seasonal cycles, whose likely cause is the absorption and release of $\mathrm{CO}_{2}$ from plants in the Northern hemisphere.

The assertion of climate change being on a path towards inflicting serious damage is based on data modelling, supported by observations of events to which global climate change is likely to have contributed [3]. Increased occurrence of floods, wildfires and crop damage 


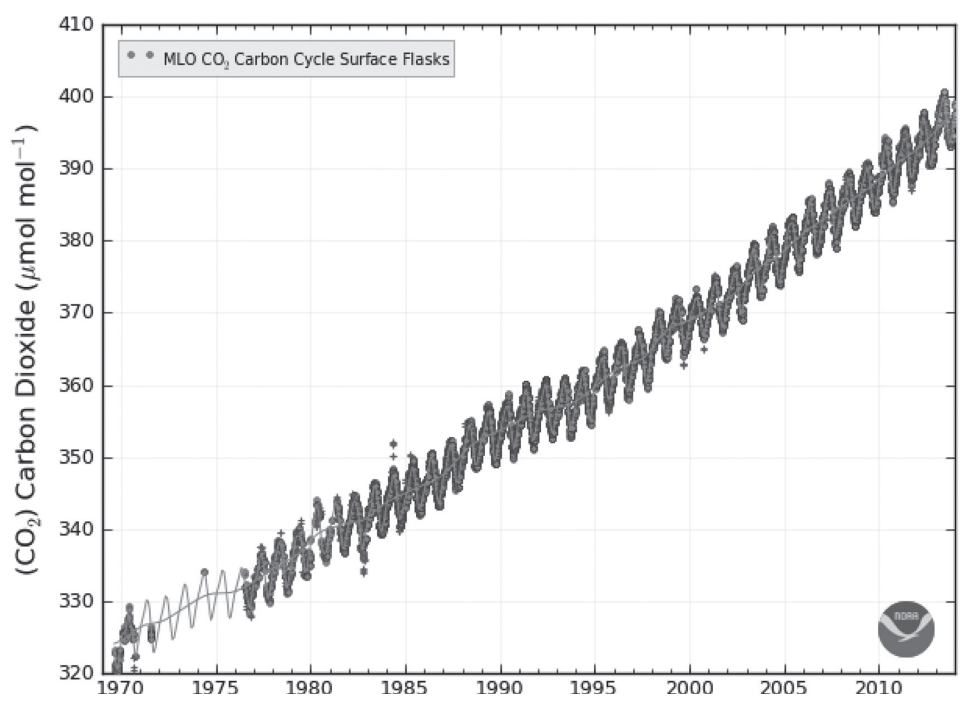

Figure 3: Atmospheric concentrations of carbon dioxide $\left(\mathrm{CO}_{2}\right)$ at Mauna Loa, Hawaii [21].

from weather conditions are among the projected consequences of climate change, which in turn can affect many peoples' lives through food shortages, inhabitability, migration and conflict.

The future impacts of energy-related emissions through climate change on the environment and on human conditions cannot be precisely forecasted or modelled. Established knowledge provides strong reason to assume that there is a significant risk of serious damage from global emissions, and that the risk increases with the cumulative amount of emissions.

A target of limiting temperature increase so as not to exceed $2^{\circ} \mathrm{C}$ was agreed internationally in 2010 within the United Nations Framework Convention on Climate Change. The target is a somewhat arbitrary negotiated result of conflicting considerations. Claims are often heard that the target is too high for the world's environment but too low for the world's combined ability to make adequate decisions. Nevertheless, being a number which carries the authority of a large international body and is readily recalled by many, the $2^{\circ}$ target is often cited as the relevant criterion for effective global climate policy.

\subsection{The global role of the energy sector}

In view of the challenges reviewed above, the global energy sector is called upon to provide an essential enabler of human progress: Those needing to be lifted out of poverty, those aspiring to substantial economic and social growth and those wanting to sustain already high levels of human development all depend on energy to be available in suitable forms and at affordable cost. Extrapolation of past developments suggests that this will require increasing amounts of energy to be supplied globally, as an increasing portion of the world's population advances towards higher levels of development. But already, the present level of fossil fuels consumption creates an unsustainable burden on the world's climate. The energy sector also needs to be part of a development in which the world's needs for energy can be met without inflicting serious damage on the climate. 


\section{PROJECTIONS}

3.1 Expectations for energy consumption to 2040

The world consumed 484 Exajoules (EJ) of energy in 2010 (not including traditional use of biomass for fuel). Oil was the main source of primary energy with $169 \mathrm{EJ}$, followed by coal (148 EJ), natural gas (119 EJ), renewables (37 EJ) and nuclear power (10 EJ). ${ }^{1}$

Several public institutions and large energy firms from time to time publish projections and scenarios for future energy consumption. A selection of these is shown in Fig. 4.

In Fig. 4, the six middle columns show different projections and scenarios which all show increased energy consumption to 2035 or 2040, essentially driven by energy demand. They show increases of 37-64\% in global energy consumption over 2010. There are two different scenarios from Shell, labelled 'Mountains' and 'Oceans'. Shell's 'Mountains' scenario represents a world of entrenched positions of power and moderate economic dynamism, whereas the 'Oceans' scenario represents a more dynamic and less controlled world. Shell's 'Oceans' scenario results in the largest energy consumption among the selected scenarios and time frame. From the United States Energy Information Administration [6] and from ExxonMobil [7], there are single projections of energy use to 2040. From the International Energy Agency [8], there are two scenarios, which differ in the assumed implementation by governments of energy related policies for which there currently are stated intents but no firm implementation plans.

The six scenarios and projections referred above all show large relative increases in the use of renewable energy both for electricity and for fuels. Renewable fuels here include modern biofuels for heating purposes (but not traditional biofuels) as well as automotive fuels made

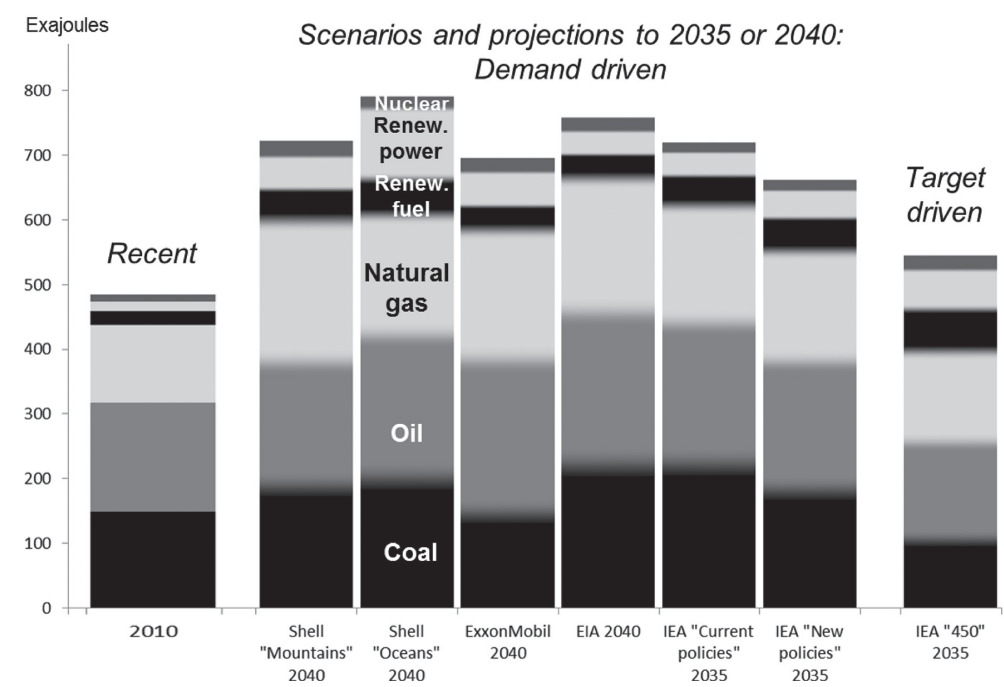

Figure 4: Global energy consumption. 2010 and selected projections and scenarios for 20352040 [4-8].

${ }^{1}$ Based on data from BP [4] and Shell [5]. Renewable and nuclear electricity are included in their amount of electricity without conversion to fossil fuel equivalents, as is done in BP's statistics. 
from biomass. In spite of the strong projected growth in renewable fuels use, they are in none of these scenarios sufficient to avoid significant increases in the use of fossil fuels.In all scenarios, natural gas is expected to have the strongest growth in absolute terms. In most scenarios, coal and oil consumption are also projected to grow, albeit less than natural gas.

All referred scenarios also stipulate that energy consumption will grow faster than the world population, but slower than the world economy. IEA's 'New Policies' scenario is based on assumed global population growth of $25 \%$, GDP growth of $130 \%$ and energy consumption growth of $33 \%$. The other scenarios differ from this mainly in projecting higher energy consumption growth. The expected difference in growth rates between the global economy and energy consumption is driven in part by improvements in energy efficiency, in part also by structural conditions whereby advanced economies grow mainly in sectors which require relatively little energy (e.g. services sectors).

\subsection{Implications for the global climate}

The six scenarios referred above have in common that they will lead to $\mathrm{CO}_{2}$ emissions which are inconsistent with the target of limiting the global temperature increase to $2 \%$ above the pre-industrial level (Section 2.3). They lend support to the assertion that the world is headed for a serious problem with the climate, and that something will have to give: Either ways must be found of supporting high levels of human development with much less energy-related emissions, or there will be much lower levels of human development than hoped for, or there will be serious changes to the global climate. The latter possibility appears most likely based on current developments.

Figure 4 shows, on its right side, a seventh scenario for energy consumption. It is designed by the IEA [8] to be consistent with limiting the global temperature increase to $2^{\circ} \mathrm{C}$. This requires limiting the long-term $\mathrm{CO}_{2}$ content in the atmosphere to $450 \mathrm{ppm}$, which can be compared with the current level of around 400 ppm shown in Fig. 3. This '450' scenario from the IEA, however, also requires large shifts towards more renewable energy after 2035. It also requires large-scale implementation of carbon capture and storage (CCS), mainly after 2035.

The '450' scenario is based on a fundamentally different premise than the others, in that it seeks to answer the question: What energy consumption can be consistent with avoiding serious damage to the climate? In contrast, the other six scenarios and projections seek to answer the question: How much energy will be consumed under anticipated conditions?

Even the ' 450 ' scenario allows for a slight increase in global energy consumption to 2035; $13 \%$ above the 2010 level. In comparison with the demand-driven scenarios, it requires much slower growth in consumption, even bigger increases in renewable energies, decreasing consumption of coal and oil, while allowing for a modest increase in natural gas consumption.

\subsection{Extractive energy reserves}

Concerns are sometimes raised about the global long-term capacity to supply oil and gas, which are considered finite resources. It will be argued here that the world is not likely to suffer from a global shortage of oil and gas reserves for the next several decades, although politically induced disturbances can cause supply constraints.

As of end 2012, the world's oil reserves were 53 times that year's production. The corresponding figure for natural gas was 56 years, and for coal 109 years [4]. If adjusted for projected increases in consumption, quantities equal to the present reserves will be depleted 


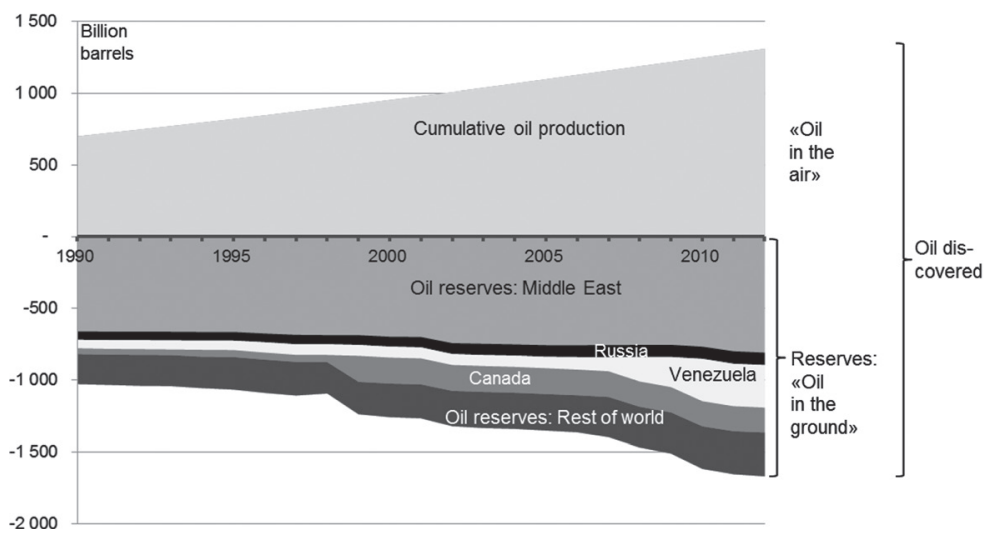

Figure 5: Global cumulative oil discoveries; produced and remaining portions [4].

faster than those numbers indicated. More importantly, however, additions are being made to reserves due to successful exploration and for other reasons.

Figure 5 indicates on a time scale the amount of oil discovered globally, the portion that has been produced (becoming 'oil in the air') and the portion remaining in the ground as reserves. A key feature of the figure is the consistent increase in reserves since 1990, indicating that extraction of oil from the underground has been more than replaced by reserve additions during nearly all those years. Another prominent feature is the large portion of reserves located in the Middle East, a condition that has often caused concerns aggravated by the persistence of conflicts in that region. Increases in reserves in the time frame shown have occurred mainly outside the Middle East, notably in Venezuela and Canada, which are now the largest oil reserve holders outside the Middle East.

Additions to global oil reserves are not solely a direct consequence of successful exploration. They result also from better understanding of reservoirs already found, and importantly from technological advances in combination with prices which allow for the profitable extraction of more oil from known resources. The large reserve additions in Venezuela and Canada comprise mainly heavy hydrocarbons whose existence had been known for some time, but whose extraction was considered unfeasible until enabled by better technologies and/or higher prices.

Additions to oil and gas reserves at recent levels cannot continue indefinitely. Reserves comprise the oil and gas whose existence in the underground is known and whose extraction considered feasible under prevailing conditions, usually with a $90 \%$ confidence. Reserves is a subset of resources, which comprise all oil and gas in the ground. For given definitions of 'oil' and 'gas', resources of oil and gas can be considered finite yet undetermined quantities. With reserves being a subset of finite resources, the potential for replenishing reserves is obviously limited at some point.

This limitation is, however, not set to constrain global energy supply for the next several decades if the global oil and gas industry continues to add large reserves, as it has indeed done consistently for several decades. Concerns have been raised that this trend will soon reverse, which would induce a peak in global reserves and the capacity to supply oil and gas. Following are some observations in support of an expectation that global reserves and supply capacities for oil and gas will hold up well. 
The price of Brent crude oil, currently the world's most significant 'marker' oil price, has remained fairly stable and mostly within a range of US\$ 100 to 115 per barrel for the past three years. ${ }^{2}$ In the 1990s, the price was usually between US\$ 10 and 20 per barrel. There are complaints that the costs of finding, developing and producing petroleum have also risen, threatening to undermine the industry's profitability in spite of the high oil and gas prices. One indicator of increasing costs of developing oil reserves is provided by the consultancy firm IHS CERA, whose Upstream Capital Cost Index increased by 130\% from year 2000 to 2012, whereas aggregate general inflation ${ }^{3}$ over the same period was $29 \%$ [9]. Numerous presentations and trade publications articles have reported of the industry being compelled to move activities into environments, which are naturally or politically inhospitable. The high price of oil can be seen as a consequence of the challenging operating conditions, and such observations underpin concerns of reserve limitations.

Increasing costs of operations, however, are a consequence as well as a cause of high prices. High prices trigger high expenditures on finding and producing oil, because high cash flows from current production provide the financial capacity, and because current high prices tend to cause high expectations also for future prices, which in turn justify investments in expensive capacity for future production. According to conventional economic theory, the prevailing price of a commodity can justify its production at unit costs up to that price. In this perspective, it is unsurprising that an increased oil price is followed by observations of increased costs of producing oil.

There have been frequent reports of capacity constraints in the industries providing inputs to petroleum exploration and production. This has allowed many such suppliers to do rather well financially and has allowed employees in certain professional categories to obtain salary levels which are clearly higher than those common in most other industries. These observations can be seen as continued effects of the large increase in oil prices over the last 15 years, the effects of which can be expected to normalise after some time. This suggests that there is elasticity in the industry's capabilities, and that the capacities to supply oil and gas are not likely to run up against any absolute limitations any time soon.

There is, however, a continued potential for disruptions of a more circumstantial nature to the supply systems for oil and gas. Since the 1973 oil embargo, they have occurred from time to time, and fears of them are a persistent feature of oil and gas markets. Since both supply and demand of oil and of gas are fairly inelastic in the short term, and the willingness to pay for spare capacities is limited, the potential for disruptions and resulting price spikes will remain.

\section{INTRODUCING SOLUTIONS: SOME GLOBAL CHALLENGES FOR ENERGY}

The broad mission for the global energy sector can be seen as supplying the energy needed for societies to pursue their potential for human development, while not causing serious harm to the environment.

Nations that are rich in natural energy resources, notably oil and gas, also face the mission of converting resources in the underground to lasting benefits for the population. This is based on the notion, which is legislated in many jurisdictions, that such resources belong to the nation, irrespective of any private ownership of the land surface. The extraction of finite resources constitute a one-off monetisation of values granted by nature, which calls for their conversion into benefits which can be enjoyed by the entire population for many generations to come [10].

${ }^{2}$ From early 2011 to March 2014 (time of writing).

${ }^{3}$ As GDP deflator. The inflation numbers are related to U.S. dollars. 
Based on these broad missions, certain key challenges can be highlighted in the arenas of technology, enterprise and national governance. The challenges reviewed below are not exhaustive.

\subsection{Challenges for technology development}

Following is a selection issues in which developments of technology, if successful, can potentially have large positive impacts on global developments. They are:

- Photovoltaics for distributed electricity supply (Section 4.1.1).

- 'Unconventional' gas supplies (Section 4.1.2).

- Nuclear energy that can be widely accepted (Section 4.1.3).

- Renewables: lower costs and better timing (Section 4.1.4).

- Carbon capture and storage (Section 4.1.5).

- Energy efficiency in all applications (Section 4.1.6).

\subsubsection{Photovoltaics for distributed electricity supply}

While photovoltaics has become a well-established technique for producing electricity, there is still a need for improvements in technology which will enable lower costs and more integration with constructed surfaces. Photovoltaics could then become an adequate source of electricity for large populations particularly in Africa and South Asia without the need for costly grid extensions, which would be powered mainly by fossil fuels. The movement towards distributed and mainly solar power supply would be aided by improvements in common electric appliances for households and small businesses allowing their operation on low-voltage and low-power levels.

\subsection{2 'Unconventional' gas supplies}

All scenarios shown in Fig. 4 anticipate increased global consumption of natural gas. As the traditional main market for natural gas as a heating fuel for the Northern hemisphere is largely saturated, the main application of the added gas supplies will be power generation. The main competing fuels for power generation are coals and natural gas. Natural gas result in around half (or less) as much $\mathrm{CO}_{2}$ emissions per unit of electricity as coal, and over the next several decades global $\mathrm{CO}_{2}$ emissions may be significantly influenced by the extent to which power will be generated from natural gas or coal.

From 2007 to 2012, China's consumption of coal increased by $42 \%$, mainly in electricity generation, and this is a key driver of growing global $\mathrm{CO}_{2}$ emissions. The world's largest consumers of coal in 2012 were China (50\%), USA (12\%), India (8\%) and Japan (3\%).

The energy markets in the United States have changed radically since 2005 due to advances in natural gas production from shale formations. Natural gas at sharply reduced prices has replaced large quantities of coal as fuel for power generation, which is the main reason for the United States to have reduced its energy-related $\mathrm{CO}_{2}$ emissions by 12\% from 2007 to 2012 (www.eia.gov). Natural gas from shale has similar composition as other natural gas, but is often labelled as 'unconventional' due to the different geological conditions and production technologies.

There is a potential for large additional gas production from shale formations in a number of countries including China. For technological and other reasons, the U.S. success story is not directly replicated there, but such hurdles may be overcome. Shale gas in China and 
certain other countries has the potential for significant favourable impacts on global $\mathrm{CO}_{2}$ emissions (and other environmental benefits, too). Shale gas extraction also can have negative environmental impacts if not properly managed, notably in terms of water consumption and possible groundwater contamination.

For the longer term and contingent upon greater advances in technology, gas hydrates represent a potentially very large source of natural gas. Global resources have been estimated to exceed combined conventional resources of coal, oil and gas, and the resources are in many cases located near countries which otherwise are susceptible to requiring large quantities of coal for power generation.

An argument against increased natural gas use is that it too is a fossil fuel, which generates $\mathrm{CO}_{2}$ emissions, and can at best defer humanity's exposure to harmful climate change if it displaces the more intensely $\mathrm{CO}_{2}$-emitting coal. Current developments indicate that the extra time that this may allow will be useful for reaching such improvements to energy efficiency, renewable energy, nuclear energy and/or CCS as will be required to stabilise the global climate.

\subsubsection{Nuclear energy that can be widely accepted}

A number of countries built nuclear fission reactors especially in the 1970s, with high expectations for a reliable and clean mainstay of future electricity supply. Had nuclear energy gained wide public acceptance, which it has in some countries but not most, the climate problem could have been distinctly less pressing today, as large emissions from coal-based power generation could have been avoided.

All scenarios shown in Fig. 4 foresee increases in global nuclear power supply, but reaching only $3 \%$ or less of finally consumed energy. A greater role for nuclear energy could reduce the climate problem, but seems contingent upon some major technological advance, so as to offer nuclear power without the potential to destroy and contaminate which is associated with present versions.

Possibly, such technological advance could come in nuclear fusion energy, which for several decades has been subject of not yet successful research. If successful in the future, it can provide a potentially very large source of energy without climate gas emissions. An internationally funded, large-scale experiment facility for nuclear fusion, ITER, is currently under construction in France (www.iter.org).

There are also aspirations of developing alternative versions of nuclear fission energy, which may avoid some disadvantages of the present versions. Thorium-based reaction is one such approach, currently pursued in India [11].

\subsubsection{Renewables: lower costs and better timing}

All scenarios shown in Fig. 4 foresee large increases in the use of renewable energy. But these are large relative increases from a modest base, and in the demand-driven scenarios, the growth in renewables is far from sufficient to offset a growing demand for fossil fuels. Only in IEA's '450' scenario, designed to meet a target rather than to meet expectations, do renewables grow sufficiently to reduce the overall demand for fossil fuels. This entails tripling the use of renewables to supply heat and power from 2010 to 2035, and quadrupling their contribution to electricity supply in the same time frame.

The currently predominant renewable electricity supply is hydropower. It can still grow, but due to limitations in the remaining hydropower potential the bulk of the growth must come from other sources: wind, solar, geothermal and ocean energy. 
Technologies exist that can make this possible, and substantial advances in electricity production from wind, solar and geothermal energies have been made in a number of countries. $7.8 \%$ of electricity consumption in the European Union was met by wind power in 2013, according to the European Wind Energy Association [12]. Generous public financial support and/or mandated quotas for renewables have been instrumental in enabling these advances, entailing financial burdens on taxpayers and energy users.

Not only is renewable power usually more costly per delivered kilowatt-hour than power generated from coal or gas (though dependent on local conditions); also, the power supply from renewables tends to be variable with natural conditions and unadapted to demand load profiles [13]. Handling this discrepancy between production and demand profiles for renewable electricity entails significant costs, and if the burden of handling it falls on conventional coal-based power stations, then it will tend to introduce inefficiencies, which offset some of the gains in avoided $\mathrm{CO}_{2}$ emissions from renewables. Hydropower with large water reservoirs and large load capacities can be better suited to alleviate this problem, especially if electricity is traded freely on large transmission lines, but this also has costs and limitations.

Scale economies in production and installation of renewable power generation have helped reduce their unit costs. The major renewable power technologies of wind and photovoltaics are already produced in volumes at which additional scale economies alone have limited scope for driving further cost reductions. The U.S. Department of Energy has reported that the average unit costs of onshore wind power in the U.S. fell sharply over the two decades to year 2000, but since then costs have seen a mixed development resulting from various influences [14].

This leaves a need for further improvements in technology to address problems, which constrain the implementation of renewable energy: Costs need to come down further, and the issue of supply intermittence and adaption to consumption loads needs to find better solutions. Improvements in technology may include incremental improvements to what is already applied, as well as inventions triggering a break with established techniques. Since renewable energy production depends on local natural conditions, improvements in technologies that have been tried but not yet found wide application, would be welcome. This includes production of electricity from forces in the ocean: waves, tide, ocean wind and salt gradients.

\subsubsection{Carbon capture and storage}

$\mathrm{CCS}$ is the capture of $\mathrm{CO}_{2}$ from combusted fossil fuels and injection into the underground, thus avoiding its accumulation in the atmosphere. The concept is best suited to large point sources of $\mathrm{CO}_{2}$, such as power stations. In some cases, the reinjection of $\mathrm{CO}_{2}$ may be directly useful as a stimulant for increased production from oil reservoirs. A number of CCS initiatives have been launched worldwide, several of them have been discontinued, and progress on CCS is described by IEA [8] as disappointingly slow.

IEA's '450' scenario (Fig. 4) includes an assumption that CCS will be implemented on a large scale globally. Without it, fossil fuel use would have to be much more restricted than shown in the scenario for the world to manage the $2^{\circ} \mathrm{C}$ limit for atmospheric heating (Section 3.2). Indeed, this limit is clearly a huge challenge even with CCS and seems entirely unrealistic without it. CCS therefore appears an essential component in future global climate management.

Several projects have been implemented in which $\mathrm{CO}_{2}$ is captured and injected to the underground. This $\mathrm{CO}_{2}$, however, derives not from combustion, but usually from produced natural gas containing large components of $\mathrm{CO}_{2}$ in the well stream, which is separated from 
the natural gas in order for the gas to meet the sales specification. At the Boundary Dam power station in Canada, a fully integrated CCS project is scheduled for completion in 2015: $\mathrm{CO}_{2}$ will be extracted after combustion of coal and injected into an oil reservoir to improve oil recovery (www.ico2n.com; www.saskpower.com).

CCS remains a concept which is set to be of critical importance for the world's climate management, requiring further development and maturing of technology to become viable on large scale.

\subsubsection{Energy efficiency in all applications}

Improving energy efficiency has been a focus of development efforts for a wide range of products and applications at least since the 1970s. Cars, airplanes, lighting, buildings, domestic appliances and many other things now generally consume significantly less energy for the functionalities that they provide, than they did in past decades.

Improvements in energy efficiency are fundamentally possible because consumers and professional energy users ultimately do not seek the energy itself, but some functionality whose provision is aided by energy. Better technologies can improve the ratios between the functionality provided and energy consumed. Better technologies can entail the introduction of entirely different technologies for a given functionality (such as LED lighting as substitution for incandescent light), or incremental improvements to existing technologies (such as improvements in combustion engines for cars). There is no reason to believe that the scope for improved energy efficiencies on many fronts will be exhausted any time soon.

\subsection{Challenges for enterprises in the energy sector}

Enterprises are needed to transform resources and technologies into products, which energy users buy in order to obtain their desired functionalities. They are also needed to develop technologies beyond the research provided by public institutions.

Enterprises in the energy sector will be called upon to fulfil important roles in meeting the global challenges for energy, i.e. supplying the energy needed and avoiding serious damage to the climate. The challenges for energy sector enterprises can be summarised as follows:

1. Find and develop hydrocarbon reserves, especially natural gas.

2. Develop and deploy technologies referred to in Sections 4.1.1-4.1.5 above (on the area of energy efficiency, Section 4.1.6, development and deployment of technologies will primarily be driven by enterprises in other sectors, but the energy sector must adapt and contribute to this).

3. Obtain finance for and carry out the large investments required to expand and upgrade energy infrastructure in many countries.

4. Maintain efficiency and profitability in their operations, so as to be able to attract capital for required investments.

5. Manage their own operations for energy efficiency.

\subsection{Political challenges for energy}

Several key activities of the energy sector are generally driven by commercial motivation, such as the production, refining and distribution of oil and its products. They can happen without much government intervention. There are, however, several aspects of the sector in which governments are called upon to provide essential functions. 
Governments need to manage hydrocarbon resources for the lasting benefit of host nations, based on the premise that the values in the ground belong to the nation and should be exploited for the benefit of present and future generations.

Governments also need to contribute to the development of energy infrastructure, which is not readily provided by commercial entities. This usually includes large and long-term investments such as the electricity grid, pipeline systems for natural gas and for district heating, and strategic energy reserves. They can often be developed in a form of joint endeavour between Governmental and private investors, but usually with an essential role for regulatory bodies and/or State-owned enterprises.

And not least, governments need to provide the regulations and incentives required to protect the climate from serious harm, given that far more hydrocarbons can be extracted than can be released to the atmosphere as $\mathrm{CO}_{2}$ without causing such harm, and that ordinary markets do not provide any incentives to avoid this.

The climate issue being a global one, governments have tried to establish a global framework for managing it, but not with any decisive success. The United Nations Framework Convention on Climate Change (UNFCCC) was adopted in 1992 (www.unfccc.int). The Kyoto Protocol, adopted in 1997 under the UNFCCC, represents to date the only substantial implementation of a global endeavour to limit damage to the climate, but its essential obligations expired in 2012. Over the years, there have been numerous other large conventions which have not yielded any effective global framework for protecting the climate.

In the absence of an effective international framework, many Governments as well as the European Union (EU) have made individual commitments to policies for limiting climate impacts from within their own jurisdictions. Such policies are in some cases driven by a combination of different motivations: Policies that are helpful for reducing climate impacts have also been motivated by limiting strategic exposure from dependence on imports (USA), limiting pollution of cities (China) and limiting the expenditures on fuel imports (many countries).

Two policy areas are highlighted below, which will be essential for meeting the global energy challenges: Appropriate pricing of energy and emissions, and energy efficient cities.

\subsubsection{Appropriate pricing of energy and emissions}

IEA [8] anticipates that countries that are rich in energy resources will contribute strongly to growing global energy consumption and related emissions over the next several decades. There is a tendency in such countries to keep domestic energy prices low through subsidies and other mechanisms, leading to high consumption relative to the standards of the domestic economy and human development. Some examples of this are indicated in Figs 1 and 2.

High energy consumption in energy-rich countries is not always an indicator of inefficiency; it can also indicate that local energy abundance provides competitive advantage in pursuing economic activities, which are energy intensive and usually export oriented. Trinidad is one such case, with its large manufacture of ammonia from natural gas.

IMF [15] estimated that subsidies for petroleum products, electricity, natural gas and coal reached US\$ 480 billion globally in 2011, corresponding to $0.7 \%$ of global GDP and $2 \%$ of global Government revenues. Oil exporters accounted for two-thirds of the amount. IMF estimates that removing the subsidies would reduce global emissions by $13 \%$. The subsidies are obviously intended to provide certain benefits for energy users, but the IMF argues that this way of spending public money creates huge economic distortions, and that it would be more wisely spent in different ways. 
There is a strong case for abolishing subsidies on fossil fuels and electricity, but the need for appropriate pricing goes further. Considered as an externality of negative consequence, conventional economics suggests that emissions of $\mathrm{CO}_{2}$ to the atmosphere should carry a negative price. There are two established methods of implementing this: Carbon tax and tradable emissions permits [16]. The debate on which among the two is the better option will not be pursued here. Clearly, however, in view of the challenge of $\mathrm{CO}_{2}$-induced climate change, a form of negative price on emissions is justified.

Ideally, the system for imposing burdens on $\mathrm{CO}_{2}$ emissions should be uniform and global. That seems unlikely to happen any time soon. Some national and regional schemes have been implemented. The EU continues to operate a system of emission permits as first established for compliance with the Kyoto Protocol. $\mathrm{CO}_{2}$ taxes are imposed on automotive fuels and a host of other fuels in several countries. They need not increase the overall tax burden in the country, as they may be offset by reductions in other taxes.

A problem, however, arises when $\mathrm{CO}_{2}$ taxes are imposed in a country with effects for industries which are internationally competitive, as this will tend to drive production and jobs away the $\mathrm{CO}_{2}$-taxing country to other countries, without necessarily saving any global $\mathrm{CO}_{2}$ emissions. Countries need to consider such effects carefully, while still applying an appropriate burden on $\mathrm{CO}_{2}$.

\subsubsection{Energy efficient cities}

An increasing portion of the world's population lives in cities. Rapid economic growth, such as China's, leads also to rapid growth of cities in terms of population and in terms of built space, as any recent visitor to China can attest.

The way cities grow depends on market forces as well as public planning. Political decisions on land use and construction in cities can have very long-term implications: Many European city dwellers' daily routines are still influenced by decisions made $800-1000$ years ago on building cathedrals. Today's city planners routinely make decisions whose impacts are likely to last for many decades and possibly centuries.

The way cities grow significantly influences energy use. Cities in the USA are generally much more extensive in area than European cities of similar population. More American city dwellers live in single-family houses and on larger plots of land, and are more dependent on cars for their daily routines. This has implications for energy requirements for homes and for transport, and is an important reason why energy consumption in the USA is much higher than in European countries of similar development level. Newman and Kenworthy [17] showed that large American cities such as Houston, Chicago, Los Angeles and New York had around three times the energy consumption per capita as large similarly sized European cities (Paris, London, Berlin and Vienna), while the latter had much higher population densities. Energy consumption in cities depends not only on population density, but also on factors such as building standards, spatial allocation of activities, energy infrastructure and the transport systems.

The high-energy consumption of American cities is a consequence of city planning decisions, which cannot easily be reversed. This points to the importance that planners of fast growing cities, of which there are many in Asia, provide for energy effectiveness and other environmental qualities.

Population density in cities does not seem to impair the quality of living there. On the contrary; the consultancy Mercer [18] has assessed the quality of living of 223 world cities, albeit from the perspective of expatriate professionals' families living there temporarily. The 20 highest ranking cities included 13 European and no U.S. cities. 
Copenhagen ranked ninth on Mercer's quality of living list and is, with 7378 inhabitants per square $\mathrm{km}$, densely populated even by European standards. The city has an ambitious plan for becoming $\mathrm{CO}_{2}$ neutral by 2025, and for making the insights gained in the process available to other cities of the world [19]. The city reduced $\mathrm{CO}_{2}$ emissions by $21 \%$ from 2005 to 2011. It is already noted for widespread use of bicycles, facilitated by road facilities designed to favour bicycles as a convenient and cheap transport in the city. A district heating system of hot water pipes carries heat from garbage incineration to heat buildings. High standards for heat insulation of buildings apply. Windmills within city limits and in the shallow sea outside will be supplemented by a biomass power generator, whose surplus heat will also feed into the district heating. Copenhagen is an example of a city which can improve on its already high environmental qualities, helped by a favourable physical configuration of the city, while preserving its position as one of the world's best cities in which to live.

\section{SUMMARY}

This paper has argued that the large challenges for the world's energy sector are to supply the energy required for societies to fulfil their potentials for human development, without inflicting serious harm to the world's climate. For national governments as custodians of resources belonging to the nation, there is also the challenge of converting those resources to lasting benefits for the population.

Based on a selection of projections and scenarios from leading institutions and energy firms, the energy sector will be capable of providing the quantities of energy required to 2040 and beyond. There is the added challenge of making suitable forms of energy available to large sections of the world population who are currently deprived of it, but this does not always require supply of energy in conventional forms. The world is also heading for a serious problem with climate change induced largely by emissions from fossil energy use. The energy sector must contribute to providing solutions to this problem.

Six issues are highlighted in which technology developments will be critical to meeting the large energy challenges: Photovoltaics for distributed power, unconventional gas resources, lower costs and improved timing for renewables, nuclear energy, which can be widely accepted, CCS, and energy efficiency in all applications.

For the political dimension of the energy sector, two critical issues are highlighted: Governments all over the world must provide for appropriate pricing of energy and emissions, so as to avoid the economic distortions from subsidies and to impose an adequate economic burden on emissions which contribute to the climate problem. And governments must plan for cities to become energy efficient, for which the plan being implemented for the city of Copenhagen is proposed as an inspirational example.

\section{REFERENCES}

[1] United Nations Development Programme (UNDP), Human Development Report, available at http://hdr.undp.org, 2013.

[2] Intergovernmental Panel of Climate Change (IPCC), Climate Change 2013, The Physical Science Basis, Working Group I Contribution to the Fifth Assessment Report of the Intergovernmental Panel of Climate Change, available at www.ipcc.ch, 2013.

[3] Intergovernmental Panel of Climate Change (IPCC), Managing the risks of extreme events and disasters to advance climate change adaptation, Summary for policymakers, available at www.ipcc.ch, 2012.

[4] BP, Statistical Review of World Energy, available at www.bp.com, 2013. 
[5] Shell, New Lens Scenarios, available at www.shell.com, 2013.

[6] United States Energy Information Administration (EIA), International Energy Outlook 2013, available at www.eia.gov, 2013.

[7] ExxonMobil, The Outlook for Energy: A View to 2040, available at www.exxonmobil. com, 2014.

[8] International Energy Agency (IEA), World Energy Outlook, 2013. doi: http://dx.doi. org/10.1787/weo-2013-en

[9] IHS, CERA Upstream Capital Cost Index, available at www.ihs.com.

[10] Al-Kasim, F., Managing Petroleum Resources. The "Norwegian Model" in a Broad Perspective. Oxford Institute for Energy Studies, 2006.

[11] International Atomic Energy Agency (IAEA), Thorium's Potential in Nuclear Power Development, available at www.iaea.org, 2011.

[12] European Wind Energy Association (EWEA), Wind in power; 2013 European statistics, available at www.ewea.org, 2014.

[13] Nagl, S., Fursch, M. \& Lindenberger, D., The costs of electricity systems with a high share of fluctuating renewables: a stochastic investment and dispatch optimization model for Europe. The Energy Journal, 34(4), pp. 151-179, 2013. doi: http://dx.doi. org/10.5547/01956574.34.4.8

[14] United States Department of Energy (U.S. DOE), Revolution now: the future arrives for four clean energy technologies, available at www.energy.gov, 2013.

[15] International Monetary Fund (IMF), IMF Energy Subsidy Reform: Lessons and Implications, available at www.imf.org, 2013.

[16] Sumner, J, Bird, L. \& Smith, H., Carbon taxes: a review of experience and policy design considerations. Technical Report December 2009, National Renewable Energy Laboratory, available at www.nrel.gov, 2013.

[17] Newman, P. \& Kenworthy, J., Sustainability and cities: Overcoming Automobile Dependence, Island Press: 1999. doi: http://dx.doi.org/10.3141/1670-04

[18] Mercer, Quality of Living Rankings Report, available at www.mercer.com, 2012.

[19] Københavns Kommune (City of Copenhagen), KBH 2025 Klimaplanen (in Danish language), available at www.kk.dk, 2012.

[20] World Bank database, available at http://data.worldbank.org.

[21] Earth System Research Laboratory (ESRL), Carbon Cycle Gases Mauna Loa, Hawaii, United States Time Series, available at www.esrl.noaa.gov, 2014. 